\title{
Essentials of recurrent aphthous stomatitis (Review)
}

\author{
CÉSAR RIVERA \\ Oral Medicine and Pathology Research Group, Department of Basic Biomedical Sciences, \\ Faculty of Health Sciences, University of Talca, Talca, Maule 3460000, Chile
}

Received March 13, 2019; Accepted June 5, 2019

DOI: $10.3892 / b r .2019 .1221$

\begin{abstract}
Recurrent aphthous stomatitis (RAS), also known as canker sores, is the most common disease of the oral mucosa. Unlike caries and periodontal disease, patients with RAS are unable to prevent it. The clinical picture of RAS is characterized by recurrent episodes of solitary or multiple painful ulcerations without association with systemic diseases. The objective of this review is to present the essential characteristics of RAS, including its definition, pathogenesis, clinical and microscopic characteristics, proposed experimental models and recommended pharmacological management. This understanding can serve as a theoretical framework for research proposals.
\end{abstract}

\section{Contents}

1. Introduction

2. Differential diagnosis and epidemiology

3. Pathogenesis

4. Clinical characteristics

5. Disease phases

6. Microscopic characteristics

7. Experimental models

8. Treatment

9. Conclusions

\section{Introduction}

Recurrent aphthous stomatitis (RAS), also known as canker sores, is the most common disease of the oral mucosa (1). This review presents key aspects of RAS, integrating clinical, histological and molecular concepts that are important for

Correspondence to: Dr César Rivera, Oral Medicine and Pathology Research Group, Department of Basic Biomedical Sciences, Faculty of Health Sciences, University of Talca, Campus Norte, Avenida Lircay S/N, Talca, Maule 3460000, Chile

E-mail: cerivera@utalca.cl

Key words: aphthae, etiology, pathogenesis, experimental models, therapeutics, review every medical professional that encounters this disease to understand.

The clinical picture of RAS is characterized by recurrent episodes of solitary or multiple painful ulcerations (2) without an association with systemic diseases (3). The latter is relevant to ensure that RAS is not confused with aphthous ulcerations.

\section{Differential diagnosis and epidemiology}

Aphthous ulcerations (or RAS-like ulcerations) have an underlying systemic cause; therefore, they should be considered as a distinct medical condition (3). The differential diagnoses should be established with autoinflammatory syndromes, including periodic fever with adenitis, pharyngitis and aphthae (PFAPA) syndrome, Behçet's syndrome and Crohn's disease; and immunodeficiency states, including nutritional defects (such as celiac disease and other gastrointestinal disorders), immune defects (such as human immunodeficiency virus infection/acquired immune deficiency syndrome) and neutrophil defects (such as cyclic neutropenia) (4). The term RAS should be used for ulceration present in the absence of systemic disease.

The prevalence of RAS varies between 0.9 and $78 \%$ in different groups examined. In the US, for the period of $1988-1994$ the prevalence was $0.89 \%$ in adults (5) and $1.64 \%$ in children (6). In Iran (2005), Jordan (2008), India (2010-2012) and China (2013-2017) reported prevalence was $25.2 \%$ (7), $70 \%$ (8), 21.7\% (9) and 27.17\% (10), respectively. Its onset appears to peak between 10 and 19 years of age (11) and its frequency decreases with advancing age (12).

\section{Pathogenesis}

The etiology and pathogenesis of RAS remain unclear. Multiple factors are associated with the establishment of this disease, including a positive family history, food hypersensitivity, smoking cessation, psychological stress and immune disturbance $(11,13)$. However, for this evidence, there is often an absence of statistical risk analysis. Immune dysregulation linked to several triggers may facilitate the development of RAS. The roles of the immune system and inflammatory processes have been confirmed in recent large-scale bioinformatics analyses $(14,15)$. It is known that a Th1-type hyperimmune response favors the appearance of inflammatory reactions that precede ulcerations (Fig. 1) (16,17). In addition, genetic risk factors can determine individual susceptibility 
to RAS; in particular, several DNA polymorphisms of the NOD-like receptor 3 (18), toll-like receptor 4 (19), interleukin (IL)-6 (20), E-selectin (21), IL-1 $\beta$ and TNF- $\alpha$ genes (22). However, despite the large number of factors examined, the underlying cause triggering the episodes of ulcers remains to be elucidated. Therefore, clinically, the emergence of new lesions cannot be avoided at present.

\section{Clinical characteristics}

RAS is known to be particularly painful (15). These idiopathic ulcerations are oval lesions of different sizes with clean edges surrounded by an erythematous halo. At the center of the ulceration, the necrotic fundus is covered with a yellow-white fibrinous exudate (23). The ulcers typically present in the non-masticatory mucosa of the cheeks, lips, ventral and lateral surfaces of the tongue, non-attached gingiva, and occasionally, the soft palate (24). RAS lesions are self-limiting (simple aphthosis), resolving within 1-2 weeks in the majority of patients (25). In those affected by the disease, the ulcers can compromise important daily functions, including nutrition, speech and oral hygiene (26), and affect quality of life (27). This is important, considering that the lesions can last $>2$ weeks, with recurrent episodes in a period of 1-4 months (11). RAS occurs in three morphological presentations: Minor-type (Mikulicz ulcers, 2-10 $\mathrm{mm}$ in diameter), which is the most common (Fig. 2); major aphthous, also termed Sutton ulcers or periadenitis necrotic mucosa ( $>10 \mathrm{~mm}$ in diameter); and herpetiform ulceration, which consists of multiple small ulcers (28). Some patients have continuous oral ulcerations; in these cases, some ulcers heal as others develop, with occasional genital ulcers. This corresponds to a clinical state known as complex aphthosis (11). Complex aphthosis has an underlying systemic cause, which does not correspond with the RAS diagnosis.

\section{Disease phases}

The disease sequence comprises the following stages: Premonition ( $24 \mathrm{~h}$ ), comprising symptoms but no visible signs of disease; pre-ulcerative (between $18 \mathrm{~h}$ and 3 days), comprising erythema and mild edema; ulcerative (1-16 days), comprising active ulceration; healing (4-35 days, usually <21 days), involving a decrease in symptoms and progressive healing; and remission, in which there is no evidence of ulcers (29). The ulcerative and remission phases are those that can be evaluated with greater objectivity on dental examination. Disease recurrence is established with the appearance of new ulcers. Disease severity can be determined based on the number, size and location of the lesions, pain, duration, ulcer-free periods (30) and the impact on patient quality of life $(27,31)$.

\section{Microscopic characteristics}

The diagnosis of RAS is eminently clinical and is based on careful examination. The incisional or excisional biopsy of ulcers is recommended only in cases of uncertainty, when the presence of an oral disease producing ulcers or a malignancy is suspected (32). The microscopic characteristics of RAS are nonspecific. The pre-ulcerative lesion shows subepithelial

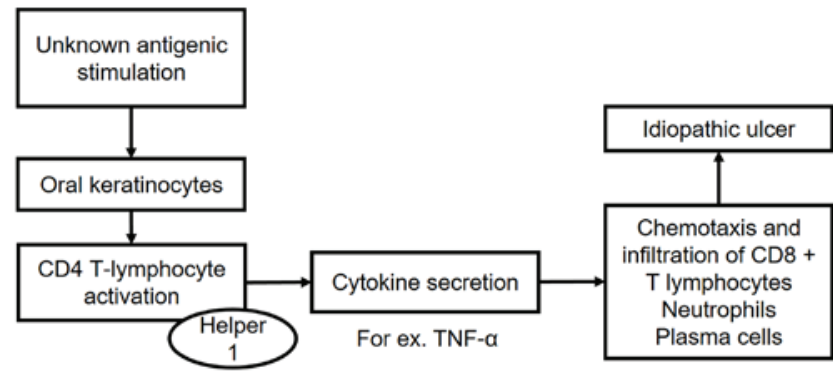

Figure 1. Cell-mediated immunity in the pathogenesis of recurrent aphthous stomatitis. Lymphocytic cells infiltrate the oral epithelium and edema develops as a result of inflammatory stimuli. Keratinocyte vacuolization and localized vasculitis cause a papular swelling. The papule ulcerates and is infiltrated by neutrophils, lymphocytes and plasma cells, followed by healing and regeneration of the epithelium. Adapted from Cui et al (24).

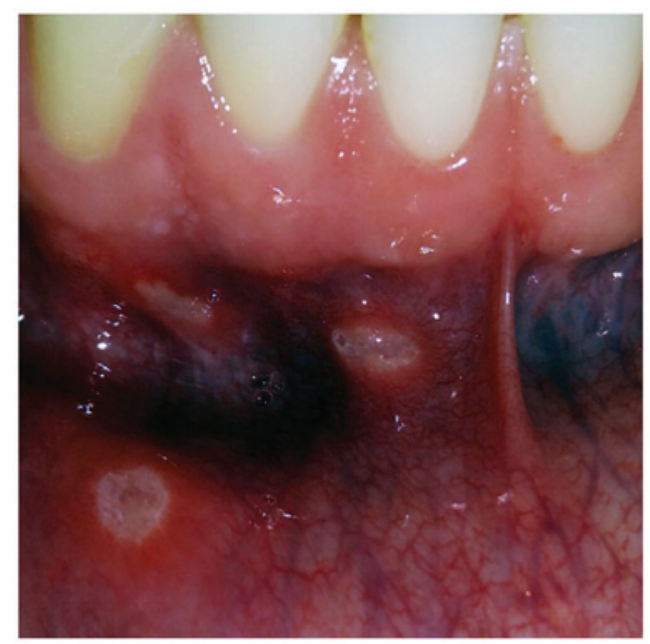

Figure 2. Small ulcers of recurrent aphthous stomatitis minor-type (Mikulicz ulcer). These ulcers are painful.

inflammatory mononuclear cells with abundant mast cells, edema of the connective tissues and neutrophils lining the margins. Damage to the epithelium usually begins in the basal layer and progresses through the superficial layers, ultimately leading to ulceration and surface exudation $(2,11)$.

\section{Experimental models}

At present, the only way to examine this disease has been in those patients who suffer from it. In the English literature, two models for the experimental evaluation of RAS have been proposed, both using rabbits. One of the models induces ulcers with $50 \%$ acetic acid $(33,34)$ and the other by surgical incision in the oral mucosa (35). Neither registered methods are involved in the inflammatory processes described in RAS. As RAS is an immunologically-mediated disease, the chemical and mechanical induction of ulcers cannot be considered valid models.

\section{Treatment}

Therapeutic alternatives focus on reducing painful symptoms (36). Clinically, dental surgeons at present can advise patients that the ulcers are likely to heal in 2 weeks, and in 
more complex cases, treatment based on topical corticosteroids can be implemented (37), which is the same approach used for several diseases of unknown cause, including pemphigus, pemphigoid and oral lichen planus. Despite the use of topical corticosteroids over several years for RAS, there is a lack of high-quality evidence for their efficacy (38) and even less for systemic interventions (31). However, the recommended protocol is a combination of a topical corticosteroid plus a topical anesthetic and a buccal antiseptic (38). The combination includes triamcinolone ( $0.1 \%$ paste, up to four times daily) in addition to topical lidocaine ( $2 \%$ viscous solution, maximum 8 doses/day) and oropharyngeal chlorhexidine $(0.12 \%, 15 \mathrm{ml}$ as a mouthwash twice daily) as an adjuvant (4). Patients should be instructed to avoid recognized trigger foods, and acidic foods and drinks (39).

\section{Conclusions}

The key concepts associated with RAS are as follows: Its cause is unknown, it cannot be prevented, it is immunologically mediated, diagnosis is clinical, there are no experimental models for its investigation, and recommended treatment includes a combination of corticosteroids and topical anesthesia plus an antiseptic. Taking these key concepts into account, several questions require further biomedical research. These include determining what the molecular differences are between a healthy individual and a patient with RAS, determining which molecules are involved in the ulcerative phase of disease and the phase of disease remission, and establishing whether there are molecules that can predict the clinical course and the severity of ulcers. Answering these questions can open up novel therapeutic and preventive possibilities.

\section{Acknowledgements}

Not applicable.

\section{Funding}

Funding was provided by Fondo Nacional de Desarrollo Científico y Tecnológico (Fondecyt; grant no. 11180170).

\section{Availability of data and materials}

Not applicable.

\section{Authors' contributions}

CR conceived the review and analyzed the relevant literature. CR sourced the literature and wrote the manuscript. CR critically revised the manuscript, produced the figures and have read and approved the final manuscript.

\section{Ethics approval and consent to participate}

Not applicable.

\section{Patient consent for publication}

Not applicable.

\section{Competing interests}

The authors declare that they have no competing interests.

\section{References}

1. Edgar NR, Saleh D and Miller RA: Recurrent aphthous stomatitis: A review. J Clin Aesthet Dermatol 10: 26-36, 2017.

2. Preeti L, Magesh K, Rajkumar K and Karthik R: Recurrent aphthous stomatitis. J Oral Maxillofac Pathol 15: 252-256, 2011.

3. Jin LJ, Lamster IB, Greenspan JS, Pitts NB, Scully C and Warnakulasuriya S: Global burden of oral diseases: Emerging concepts, management and interplay with systemic health. Oral Dis 22: 609-619, 2016.

4. BMJ Best Practice: Aphthous ulcers 2018. https://bestpractice. bmj.com/topics/en-us/564/guidelines. Accessed April 26, 2018.

5. Shulman JD, Beach MM, Rivera-Hidalgo F: The prevalence of oral mucosal lesions in U.S. adults: data from the Third National Health and Nutrition Examination Survey, 1988-1994. J Am Dent Assoc 135: 1279-86, 2004.

6. Shulman JD: Prevalence of oral mucosal lesions in children and youths in the USA. Int J Paediatr Dent 15: 89-97, 2005.

7. Davatchi F, Tehrani-Banihashemi A, Jamshidi AR, ChamsDavatchi C, Gholami J, Moradi M, Akhlaghi M, Foroozanfar MH, Barghamdi M, Noorolahzadeh E, et al: The prevalence of oral aphthosis in a normal population in Iran: a WHO-ILAR COPCORD study. Arch Iran Med 11: 207-209, 2008.

8. Safadi RA: Prevalence of recurrent aphthous ulceration in Jordanian dental patients. BMC Oral Health 9: 31, 2009.

9. Patil S, Reddy SN, Maheshwari S, Khandelwal S, Shruthi D and Doni B: Prevalence of recurrent aphthous ulceration in the Indian Population. J Clin Exp Dent 6: e36-e40, 2014.

10. Wang H, He F, Xu C, Fang C and Peng J: Clinical analysis for oral mucosal disease in 21972 cases. Zhong Nan Da Xue Xue Bao Yi Xue Ban 43: 779-783, 2018 (In Chinese).

11. Akintoye SO and Greenberg MS: Recurrent aphthous stomatitis. Dent Clin North Am 58: 281-297, 2014.

12. Chavan M, Jain H, Diwan N, Khedkar S, Shete A and Durkar S: Recurrent aphthous stomatitis: A review. J Oral Pathol Med 41: 577-583, 2012.

13. Gallo Cde B, Mimura MA and Sugaya NN: Psychological stress and recurrent aphthous stomatitis. Clinics (Sao Paulo) 64: 645-648, 2009.

14. Rivera C: Immune system and zinc are associated with recurrent aphthous stomatitis. An assessment using a network-based approach. J Oral Res 6: 245-251, 2017.

15. Wu J, Chen ZP, Shang AQ, Wang WW, Chen ZN, Tao YJ, Zhou Y and Wang WX: Systemic bioinformatics analysis of recurrent aphthous stomatitis gene expression profiles. Oncotarget 8: 111064-111072, 2017.

16. Mimura MAM, Borra RC, Hirata $\mathrm{CHW}$ and de Oliveira Penido N: Immune response of patients with recurrent aphthous stomatitis challenged with a symbiotic. J Oral Pathol Med 46: 821-828, 2017.

17. Ślebioda Z, Krawiecka E, Szponar E and Dorocka-Bobkowska B: Evaluation of serum zinc levels in patients with recurrent aphthous stomatitis (RAS). BMC Oral Health 17: 158, 2017.

18. Slezakova S, Borilova Linhartova P, Masopustova L, Bartova J, Petanova J, Kuklinek P, Fassmann A, Dusek L and Izakovicova Holla L: Association of the NOD-like receptor 3 (NLRP3) gene variability with recurrent aphthous stomatitis in the Czech population. J Oral Pathol Med 47: 434-439, 2018.

19. Karasneh J, Bani-Hani M, Alkhateeb A, Hassan A, Alzoubi F and Thornhill M: TLR2, TLR4 and CD86 gene polymorphisms in recurrent aphthous stomatitis. J Oral Pathol Med 44: 857-863, 2015.

20. Karakus N, Yigit S, Rustemoglu A, Kalkan G and Bozkurt N: Effects of interleukin (IL)- 6 gene polymorphisms on recurrent aphthous stomatitis. Arch Dermatol Res 306: 173-180, 2014.

21. Alkhateeb A, Karasneh J, Abbadi H, Hassan A and Thornhill M: Association of cell adhesion molecule gene polymorphisms with recurrent aphthous stomatitis. J Oral Pathol Med 42: 741-746, 2013.

22. Guimarães AL, Correia-Silva Jde F, Sá AR, Victória JM, Diniz MG, Costa Fde O and Gomez RS: Investigation of functional gene polymorphisms IL-1beta, IL-6, IL-10 and TNF-alpha in individuals with recurrent aphthous stomatitis. Arch Oral Biol 52: 268-272, 2007. 
23. Schemel-Suárez M, López-López J and Chimenos-Küstner E: Oral ulcers: Differential diagnosis and treatment. Med Clin (Barc) 145: 499-503, 2015 (In Spanish).

24. Cui RZ, Bruce AJ and Rogers RS III: Recurrent aphthous stomatitis. Clin Dermatol 34: 475-481, 2016.

25. Rogers RS III: Recurrent aphthous stomatitis: Clinical characteristics and associated systemic disorders. Semin Cutan Med Surg 16: 278-283, 1997.

26. Lalla RV, Choquette LE, Feinn RS, Zawistowski H, Latortue MC, Kelly ET and Baccaglini L: Multivitamin therapy for recurrent aphthous stomatitis: A randomized, double-masked, placebo-controlled trial. J Am Dent Assoc 143: 370-376, 2012.

27. Rajan B, Ahmed J, Shenoy N, Denny C, Ongole R and Binnal A: Assessment of quality of life in patients with chronic oral mucosal diseases: A questionnaire-based study. Perm J 18 : e123-e127, 2014

28. Albrektson M, Hedström L and Bergh H: Recurrent aphthous stomatitis and pain management with low-level laser therapy: A randomized controlled trial. Oral Surg Oral Med Oral Pathol Oral Radiol 117: 590-594, 2014.

29. Vucicevic Boras V and Savage NW: Recurrent aphthous ulcerative disease: Presentation and management. Aust Dent J 52: 10-15; quiz 73, 2007.

30. Tappuni AR, Kovacevic T, Shirlaw PJ and Challacombe SJ: Clinical assessment of disease severity in recurrent aphthous stomatitis. J Oral Pathol Med 42: 635-641, 2013.

31. Brocklehurst P, Tickle M, Glenny AM, Lewis MA, Pemberton MN, Taylor J, Walsh T, Riley P and Yates JM: Systemic interventions for recurrent aphthous stomatitis (mouth ulcers). Cochrane Database Syst Rev: CD005411, 2012.
32. Belenguer-Guallar I, Jiménez-Soriano Y and ClaramuntLozano A: Treatment of recurrent aphthous stomatitis. A literature review. J Clin Exp Dent 6: e168-e174, 2014.

33. Karavana Hizarcioğlu SY, Sezer B, Güneri P, Veral A, Boyacioğlu H, Ertan G and Epstein JB: Efficacy of topical benzydamine hydrochloride gel on oral mucosal ulcers: An in vivo animal study. Int J Oral Maxillofac Surg 40: 973-978, 2011.

34. Karavana SY, Gökçe EH, Rençber S, Özbal S, Pekçetin C, Güneri $P$ and Ertan G: A new approach to the treatment of recurrent aphthous stomatitis with bioadhesive gels containing cyclosporine A solid lipid nanoparticles: In vivo/in vitroexaminations. Int J Nanomedicine 7: 5693-5704, 2012.

35. Fernandes Teixeira FM, Figueiredo Pereira Md, Gomes Ferreira NL, Miranda GM and Andrade Aguiar JL: Spongy film of cellulosic polysaccharide as a dressing for aphthous stomatitis treatment in rabbits. Acta Cir Bras 29: 231-236, 2014.

36. Dan S, Jinwei Z, Qiang Z, Jianwei S and Weijun Z: Exploring the molecular mechanism and biomarker of recurrent aphthous stomatitis based on gene expression microarray. Clin Lab 63: 249-253, 2017.

37. Swain SK, Gupta S and Sahu MC: Recurrent aphthous ulcers-still a challenging clinical entity. Apollo Med 14: 202-206, 2017.

38. Staines K and Greenwood M: Aphthous ulcers (recurrent). BMJ Clin Evid 1303, 2015.

39. Scully C: Clinical practice. Aphthous ulceration. N Engl J Med 355: 165-172, 2006. 